\title{
SAMUEL RAMOS Y EL GÉNERO ENSAYÍSTICO: EL PERFIL DEL HOMBRE Y LA CULTURA EN MÉXICO (1934) COMO ENSAYO CAMUFLADO*
}

\author{
Eugenia Houvenaghel ${ }^{* *}$
}

\begin{abstract}
Resumen
La insistente exploración de la identidad mexicana se realiza tradicionalmente a través del género ensayístico. ¿Pero fue el ensayo siempre considerado el género idóneo para estudiar la mexicanidad? Para contestar esta pregunta, nos remontamos a El Perfil del hombre y la cultura en México (1934) de Samuel Ramos, el iniciador del examen de la idiosincrasia mexicana, con el fin de indagar en qué medida el texto pionero de Ramos se inscribe en el género literario ensayístico. Para ello nos basamos metodológicamente en la tipología del ensayo tal como lo propone Gómez Martínez (1992). Comprobamos una discrepancia entre la forma genérica que Ramos simula en su texto -la de un tratado científico-y la verdadera constitución de su texto -la de un ensayo-. Esta situación se debe entender en el marco histórico del caótico debate postrevolucionario acerca de la mexicanidad cuya carencia de sistema y lógica lleva Ramos a una preferencia por lo científico y lo metódico.
\end{abstract}

Palabras clave: Ensayo, ciencia y arte, identidad mexicana, complejo mexicano de inferioridad.

\section{SAmuel RAmos AND the literary GENRE OF the EsSAY: The profile of MAN and CULTURE in MEXico (1934) AS A CONCEALED ESSAY}

\begin{abstract}
The exploration of Mexican identity that has caracterized the Mexican literature over the past century, has traditionally been carried out in the literary genre of the essay. But has the essay always been considered the ideal genre to study Mexicanity? To answer this question, we turn to The profile of man and culture in Mexico (1934) by Samuel Ramos, the initiator of the reflection on Mexican idiosyncrasy. Our analysis examines the relationship between this pioneering text on Mexicanity and the literary genre of the essay. Methodologically, we rely on the Theory of the essay by Gómez Martínez (1992). We unveil a discrepancy between the text genre the author imitates -the scientific treatise- and the true nature of his text -the essay-. In the context of the ungoing national debate on Mexicanity, a chaotic discussion, Ramos' preference for a more rational and systematic approach to Mexican identity that is reflected in the literary form of his Profile is perfectly explicable.
\end{abstract}

Keywords: Essay, science and arts, Mexican identity, Mexican complex inferiority.

Recibido: 20-11-2013

Aceptado: 19-02-2014

* $\quad$ Proyecto de investigación (UGent - BOF): Form and structure of the Mexican essay in a historical perspective: from the cry of Dolores (1821) to the massacre of Tlatelolco (1968).

* Licenciada en Filología Románica de la UA Amberes Bélgica. Doctora en Literatura Hispanoamericana en la UGent (Gante, Bélgica). Especialista en ensayo mexicano con la beca del FWO-Vlaanderen. Académica de investigación (BOF) de literaturas hispánicas en el departamento de español de la UGent. eugenia.houvenaghel@ugent.be. 


\section{Introducción: El ensayo, ¿género idóneo para explorar "lo mexicano"?}

El ensayo es tradicionalmente el género forjador de identidades en América Latina. El caso de México es ejemplar: la insistente exploración de "lo mexicano" ${ }^{1}$ por parte de escritores e intelectuales se desarrolla principalmente en el género ensayístico. ${ }^{2}$ Octavio Paz (1950), Leopoldo Zea (1953) Carlos Monsiváis (1976), Carlos Fuentes (1977), Roger Bartra (1987), y Agustín Basave (2011), tantos escritores que —entre muchos otros- "descifran" la esencia de lo mexicano a través del mismo género: el ensayo. ¿Pero ha sido este vínculo entre el género ensayístico y el examen de la identidad mexicana siempre tan estrecho? ¿Existió ya desde las primeras manifestaciones de la introspección mexicana? Para contestar a esta pregunta, nos remontamos al inicio de la reflexión acerca de la mexicanidad. Dejando de lado los escritos pioneros de Caso (1924) y Vasconcelos (1925) que se aproximan al tema de la identidad nacional en los primeros años después de la Revolución, podemos situar este punto de arranque en 1934 cuando aparece El Perfil de hombre y la cultura en México ${ }^{3}$ de Samuel Ramos. En El laberinto de la soledad, Octavio Paz destaca la posición de El Perfil que constituye "el inicio formal de la busca de la mexicanidad" y afirma que su autor "inicia el examen del mexicano" y describe el texto como "la primera tentativa seria para conocernos" (26, el destacado es nuestro).

Samuel Ramos (1897-1959) publica su trabajo en los años treinta, cuando está en su apogeo la polémica nacionalista cuyo hilo conductor es el análisis de cómo ha de ser la cultura mexicana de la postrevolución. En efecto, la Revolución de 1910 fue el catalizador inmediato de la reflexión acerca de lo mexicano. Después de la Revolución, se intensifica en el México de las décadas de los veinte y los treinta, de grandes cambios sociales, la discusión acerca de la identidad nacional. La pregunta nacionalista recibe respuestas variadas desde diversos ámbitos del quehacer cultural. Estas réplicas quedan plasmadas en obras musicales, teatrales, literarias, plásticas (los muralistas tales como Diego

1 La mexicanidad es definida por Leopoldo Zea como "el movimiento tendiente a captar el espíritu de México, el sentido de lo mexicano y el ser o modo de ser del hombre de esta realidad"(7).

2 Hay excepciones, tal como la obra de teatro El gesticulador (1938) de Roberto Usigli. A partir de los 80, se ha llevado el discurso de la mexicanidad a otros medios comunicativos más allá del ensayo: el cine y la televisión. Pensemos en las películas como Mecánica Nacional (1979), México, México Ra, Ra, Rá (1983), De la Calle (1997) o Amores Perros (1999). Véase: Caloca (2).

3 En adelante abreviaremos: El Perfil. Citamos de la edición de 1951. 
Rivera y José Clemente Orozco), antropológicas, históricas y demás disciplinas artísticas e intelectuales. Dentro del marco de este debate, Samuel Ramos publica en 1931 el artículo "La cultura criolla" en la revista Contemporáneos. Esta contribución a la polémica se convertirá posteriormente en el cuarto capítulo de su trabajo El Perfil, en el que el autor propone su aproximación a la identidad nacional mexicana que nos ocupa en este estudio.

Situado así el inicio de la reflexión de la mexicanidad en El Perfil de Samuel Ramos, nos proponemos investigar la manera en la que este texto se relaciona con el género ${ }^{4}$ ensayístico, que se manifestará posteriormente como el género predilecto para el discurso mexicano de la autodefinición. Para ello, nos basamos metodológicamente en la tipología del ensayo de José Luis Gómez Martínez (1992) ${ }^{5}$. Confrontaremos los rasgos típicos del género, descritos en su Teoría del ensayo, con las características del texto de Ramos. Tres componentes destacados como esenciales en la tipología del ensayo estructurarán nuestro trabajo: la perspectiva subjetivista, el carácter dialogal y, finalmente, la voluntad de estilo.

Este análisis centrado en la forma literaria de El Perfil sacará a la luz una discrepancia entre la forma que Ramos quiere y pretende realizar en El Perfil el tratado científico y la verdadera índole genérica de su texto -el ensayo-. En las reflexiones finales, trataremos de entender y comentar esta discrepancia. Planteamos la hipótesis de que Ramos considera el género ensayístico como inferior al tratado científico y produce un texto cuyos rasgos se orientan a compensar sus supuestos defectos. Según nuestra hipótesis, su actitud negativa frente al género ensayístico se debe entender en el marco histórico de la reflexión acerca de la mexicanidad y, más específicamente, en la dinámica que se establece entre un nuevo enfoque más científico sobre el tema de la mexicanidad y el abordaje anterior, anti-científico de la cuestión.

4 Hablamos de "género del ensayo", pero en rigor se podría denominar un archigénero, recurriendo a los términos de Genette (1979) quien habla del archigénero ensayístico, una "forma genérica abierta a múltiples géneros cuyas características textuales implican una acción pragmática ya que el ensayista instituye en su escritura el discurso reflexivo-persuasivo".

5 En adelante abreviaremos: TdE (Teoría del Ensayo), seguido por el capítulo en números árabes. La Teoría del Ensayo se compone de 20 capítulos: 1. Hacia una definición del ensayo; 2. Orígenes y desarrollo del ensayo; 3. La palabra ensayo y su uso en España; 4. La codificación del texto y el autor implícito; 5. Actualidad del tema tratado; 6 . El ensayo no pretende ser exhaustivo; 7 . El ensayo y el especialista; 8. Imprecisión en las citas; 9 . Lo subjetivo en el ensayo: el ensayo como confesión; 10. El carácter dialogal del ensayo; 11. El ensayo como forma de pensar; 12. Continuación de los ensayos en orden cronológico; 13. El ensayo carece de estructura rígida; 14 . Las digresiones en el ensayo; 15. El ensayo en su función de sugerir al lector; 16. El lector de ensayos debe ser miembro activo; 17. De cualquier pretexto puede nacer un ensayo; 18. La volunta de estilo en el ensayo; 19. Forma y clasificación en el ensayo; 20. El ensayo y las formas de expresión afines. 


\section{Análisis}

\subsection{La verdad subjetiva del ensayo}

"Aún en las más dispares y contradictorias definiciones del ensayo, siempre ha habido una característica común: su condición subjetiva" (TdE 9). Partiendo de la esencia subjetiva del ensayo, se puede considerar el ensayo como "proyección del autor" ya que, según la célebre frase de Montaigne, la materia del ensayo es la personalidad del propio ensayista. Es en este sentido que los ensayos "son la verdadera autobiografía intelectual y emocional" del ensayista (TdE 11). Los sentimientos y las emociones del propio ensayista constituyen la base en la que se construye la perspectiva subjetivista sobre la materia tratada. En este enfoque subjetivo se halla, precisamente, el valor muy particular del ensayo. Cuando releemos El Perfil prestando atención al nivel de la presencia del ensayista, vemos que la obra no centraliza la propia experiencia personal del ensayista, sino que se aleja del carácter subjetivo e íntimo del ensayo, ya que Ramos recurre a la borradura del yo de su texto, usando la primera persona plural, empleando giros pasivos e impersonales. Evita tanto el uso explícito del yo en su texto como la referencia explícita a experiencias, sentimientos o recuerdos personales.

Más aún, la imagen que el ensayista construye de sí mismo en El Perfil, no es nada personal ni emocional sino que insiste, precisamente, en el tono racional y lógico de su trabajo y en el método científico con el que ha sido concebido. En la primera página de El Perfil, Ramos destaca que la duda científica está a la base de su obra: "A ejemplo del método cartesiano, que nos sirva esta duda para justificar la investigación que ahora vamos a emprender" (El Perfil 7-8). A lo largo de su trabajo, Ramos pone en tela de juicio lo expuesto en sus ensayos, haciéndose preguntas críticas acerca de lo que acaba de afirmar (El Perfil 12, 27, 53, 97), insertando figuras contrastivas que expresan la opinión contraria a la suya (El Perfil 29, $83,95)$, juzgando las explicaciones que acaba de dar como insuficientes (El Perfil 42). En el capítulo crucial de El Perfil, que contiene el análisis del mexicano basado en el sentimiento de inferioridad, Ramos subraya que la idea del complejo de la inferioridad del mexicano no es nueva y destaca que la novedad y la originalidad de su trabajo no residen en este concepto, sino en el método sistemático que va a aplicar a esta idea: 
Ya otros hablaron antes del sentido de inferioridad de nuestra raza, lo que por primera vez se intenta en este ensayo, es el aprovechamiento metódico de esta vieja observación [del sentimiento de inferioridad del mexicano], aplicando rigurosamente las teorías psicológicas de Adler al caso mexicano. (73)

Ramos destaca su perspectiva científica y vincula su discurso explícitamente con la metodología del psicólogo y psiquiatra austriaco Alfred Adler (1870-1937), formado en la universidad con Sigmund Freud y que funda una escuela neufreudiana de psicoanálisis basada en el sentimiento de inferioridad. Adler elabora, en sus obras más conocidas Práctica y teoría de la psicología individual (1918) y El sentido de vivir (1933), una racionalización del sentimiento de inferioridad que debe engendrar en el paciente la voluntad de remediar el complejo. Ramos insiste en que la originalidad de su proyecto se halla en la sistematicidad: "nadie, que sepamos, se ha valido sistemáticamente de esta idea [del complejo de la inferioridad] para explicar nuestro carácter"(El Perfil 73).

En un lugar estratégico de El Perfil -la primera parte del primer capítulo titulada significativamente "El método" - encontramos otra referencia al carácter metódico del trabajo. El método utilizado, explica Ramos, es doble y se basa en las teorías de dos pensadores europeos: por un lado, el perspectivismo histórico de Ortega y Gasset y por otro, el psicoanálisis de Alfred Adler.

Consideremos más en detalle el primer componente de su combinación científica: Ortega y Gasset y recurrimos, para ello, a otro estudio de Ramos, su Historia de la filosofía en México, publicado unos diez años después de El Perfil, en 1943. En este escrito posterior, el autor relata la génesis de El Perfil. El autor de este último recuerda que, aunque ya tiene en mente las ideas para el libro en los años 30 y 31, siguió buscando un método filosófico que le permitiera resolver científicamente el problema, y refiere que encontró, por ende, una parte de este método en el perspectivismo de Ortega y Gasset. Ramos explica por qué dicho perspectivismo le concedió el instrumento metodológico que le faltaba para definir lo mexicano en El Perfil:

En esta frase de Ortega yo soy yo y mi circunstancia y si no la salvo a ella no me salvo yo, veía una norma que aplicar a México, cuya realidad y cuyos problemas eran completamente 
desconocidos para la filosofía. La meditación filosófica podía muy bien servir a la definición de la circunstancia mexicana, a la determinación de lo que es o puede ser una cultura, tomando en cuenta las modalidades propias de nuestra historia y la forma en que estas han modelado la fisonomía peculiar del hombre mexicano. (Historia 153)

Por lo que es del segundo componente de su combinación científica, vemos que Adler, en su análisis neofreudiano del desarrollo individual, subrayó el papel de los sentimientos de inferioridad, más que el papel de las pulsiones sexuales, como la motivación básica subyacente a la conducta humana. Para Adler, los sentimientos de inferioridad conscientes o inconscientes -a los que denominó "complejo de inferioridad"- combinados con mecanismos compensatorios de defensa, eran las causas básicas de su carácter psicopatológico. Según Ramos, sólo es posible definir la mexicanidad combinando la teoría de las limitaciones históricas (el perspectivismo) y la doctrina de los rasgos psicológicos, dos teorías que, en la presentación de Ramos en El Perfil, son mutuamente complementarias:

Las modernas doctrinas psicológicas nos enseñan que no es posible definir el carácter individual de un hombre si no se conocen ciertas experiencias de la vida infantil que enduzan definitivamente la evolución del alma. Debemos remontarnos entonces al comienzo de nuestra historia para averiguar si hubo algún hecho capaz de proyectar la evolución del alma mexicana dentro de una órbita determinada. (32)

Entre las estrategias que contribuyen a la construcción de una imagen racional y científica del autor, conviene mencionar también el gran número de citas de autoridades que Ramos inserta en su propio texto, refiriéndose de modo científico en una nota al pie de la página a sus fuentes bibliográficas. Se trata a veces de autoridades -europeas en su mayoría- en el terreno de la psicología, pero más extensos y frecuentes son las citas de prestigiosos filósofos de la cultura tales como Hegel, Curtius, Keyserling, Spengler, Scheler (El Perfil 47, 64, 74, 133, 136, 159). ${ }^{6}$

6 El uso de notas no es característico del ensayo. Gómez Martínez comenta ("8. Imprecisión en las citas") en este marco que "el verdadero ensayista [...] sólo en ocasiones muy especiales hará uso de notas al pie de la página" mientras que, por lo general, mantiene una actitud de poca precisión ante los datos de la cita, sin que esta actitud quite la eficacia del contenido de la cita. Recalca que "esta característica es tan antigua como el ensayo mismo, y una de sus diferencias básicas con el estudio científico, cuyo valor primordial es precisamente la aportación de datos". 
Resumiendo podemos decir que la personalidad del autor en gran parte se elimina en El Perfil. Como consecuencia, el texto en nada se aproxima al carácter de una autobiografía íntima, propio del ensayo. La imagen que el yo-ensayista se construye explícitamente de sí mismo se basa en rasgos vinculados con una actitud científica y una intención o voluntad de aproximarse como un científico al tema de la idiosincrasia mexicana. Lejos de compartir experiencias personales o emociones individuales con el lector, el escritor insiste en el carácter metodológico, sistemático y científico de su reflexión. Sin embargo, destaca Gómez Martínez, en el ensayo no tiene cabida "el pensamiento filosófico sistemático ni el objetivismo científico" (TdE 9). La verdad del ensayo reside en el enfoque subjetivo que se adopta sobre la materia; no se persigue en el ensayo la verdad científica que Ramos pretende alcanzar.

En realidad, y subyacente a esta capa de objetividad, encontramos valoraciones personales del autor, por ejemplo, sobre la cultura azteca, sobre el trabajo de los misioneros o sobre las clases sociales más bajas (El Perfil 10, 24, 42, 97, 101) y muestras de introspectividad que abren una perspectiva más personal sobre la temática tratada (El Perfil 27, 83). Con todo, no podemos dar una respuesta unívoca a la pregunta acerca de la manera en la que la perspectiva subjetivista caracterizadora del yoensayista sí o no se plasma en el texto de Ramos. Por un lado, el autor insiste en que el valor de su texto se relaciona con la perspectiva objetiva y científica -la busca sistemática, la preocupación por la precisión de las citaciones, el cuidado de la metodología, la actitud rigurosa- y no con la perspectiva subjetivista tan idiosincrática del ensayo. Por otro, sin que el autor lo diga explícitamente, sí se hallan en el texto muestras, menos numerosas y menos llamativas, de la impronta personal y subjetiva del propio autor en El Perfil. Bien se puede decir que esta autodefinición como un escritor científico y objetivo representa al autor ideal que Ramos se propone ser.

\subsection{El carácter conversacional del ensayo}

El ensayo es esencialmente "comunicativo" y se propone "establecer un lazo de diálogo íntimo entre el ensayista y el lector" (TdE 10). El ensayista dialoga con sus lectores, los invita a participar activamente en el proceso de la reflexión ensayística a través de preguntas e interpelaciones. Esta interacción es tan intensa, que el ensayista con frecuencia "evita hacer referencia al proceso de escribir al referirse a su obra, y prefiere 
suponer que ha estado conversando con el lector" (TdE 10). El ensayo necesita, por lo tanto, de un lector activo para poder realizar su esencia dialogal. (TdE 16)

El Perfil incluye frecuentemente referencias a este lector activo y participante, típico del ensayo. Como consecuencia, las preguntas que preven la posible duda del lector acerca de lo expuesto son una constante en El Perfil ("el lector se preguntará si”, "el lector objecionará que"...). Ramos invita al lector a participar activamente en la búsqueda de argumentos que pueden confirmar la tesis presentada en el análisis: "el lector [...] encontrará en sus propias observaciones los datos para comprobarlas [las ideas expuestas]" (74).

Además, Ramos no deja de estimular en sus lectores una actitud receptiva tan racional y científica que posible, sobre todo en aquellos pasajes de su texto que podrían suscitar una reacción emocional. Pensemos por ejemplo en la introducción del psicoanálisis del mexicano, en la cual Ramos invita el lector a no dejarse llevar por la emoción y a penetrar en sus ideas "con entera ecuanimidad" (75). En otro pasaje, al referirse al estudio del lenguaje machista del "pelado" Ramos sugiere que el lector adopte la actitud científica del psicólogo y evite la reacción emocional: "El lector no debe tomar a mal que citemos aquí palabras que en México no se pronuncian más que en las conversaciones íntimas, pues el psicólogo ve a través de su vulgaridad y grosería otro sentido más noble" (78-79).

El carácter conversacional sí se manifiesta en El Perfil, pero es de notar que el lector que dialoga con el ensayista de este texto se construye de manera paralela a este: al enunciador científico y sistemático El Perfil corresponde un lector también racional y crítico. Efectivamente, se supone que el lector, como participante en la interacción sigue el mismo método de duda sistemática que Ramos propone. Tenemos, pues, que matizar nuestra respuesta a la pregunta de saber si se realiza el carácter dialogal del ensayo en El Perfil: por una parte sí se incluyen múltiples interpelaciones a un lector activo, por otra, este lector activo se caracteriza, sobre todo, por preocupaciones vinculadas con la metodología, duda crítica y sistematicidad propias de la ciencia.

El carácter dialogal del ensayo se vincula estrechamente con el carácter inacabado, no terminado del género y con su carácter poco sistemático: el lector, en vez de recibir del ensayista pensamientos ya preestablecidos, 
colabora de manera activa en el proceso dialogal del ensayo. De ahí que, para el ensayista, el método es secundario e incluso negativo ya que se considera un elemento limitador de la libertad reflexiva y creativa del autor. "Mientras el científico, una vez establecido el propósito de su investigación, pierde en gran medida la libertad al verse forzado a seguir el orden que su método le determina, el ensayista es libre de continuar, aplazar o simplemente interrumpir el tema comenzado" (TdE 13). De ahí que otro rasgo clave del ensayo, entendido como una conversación con el lector, es su estructura flexible y abierta que ofrece la posibilidad de tratar un tema de manera libre, asistemática y sin orden preestablecido. "En el tratado [...] destaca lo metódico, mientras que en el ensayo prevalece lo aforístico" (TdE 13).

Cuando analizamos la estructura El Perfil, vemos cómo el doble método histórico-psicológico de Ramos y su propósito científico determinan la organización global del texto. Como si el problema de México fuera un paciente que estaba pasando sesiones de un psiquiatra, Ramos presenta, en el primer capítulo, el problema del paciente mexicano, es decir, el complejo de inferioridad, que se debe suponer en todos los individuos que manifiestan una exagerada preocupación por afirmar su personalidad. En el segundo capítulo, investiga el pasado del paciente en búsqueda de eventos e influencias de importancia. Destaca concretamente la discrepancia entre el nivel cultural de la joven Hispanoamérica y de la vieja Europa. Lo que el mexicano realiza en la cultura es inferior a lo que se propone alcanzar culturalmente, y de esta gran desproporción entre lo que desea realizar y lo que puede hacer nace el sentimiento de inferioridad. Sobre la base de esta investigación histórica, que aclara las razones del complejo de inferioridad, construye un gráfico del comportamiento mexicano, en el capítulo III y IV, en el que describe las consecuencias de este complejo de inferioridad en la vida diaria y en la vida cultural del paciente. En las clases bajas, el complejo de inferioridad se expresa a través de una actitud violenta y agresiva, en las clases altas, a través de una cortesía exagerada. En la cultura, el sentido de inferioridad lleva a la imitación de la cultura superior. Por último, en el capítulo $\mathrm{V}$, el paciente se discute en el contexto de su reintegración en la sociedad y en el mundo.

Comprobamos que, hablando de la estructura general, es decir, la división en capítulos, podemos efectivamente reconocer un plan de trabajo sistemático y una lógica inherente a la aproximación global 
de Ramos al tema. Sin embargo, cuando estudiamos más en detalle la estructura, descubrimos que la organización del material dista de ser tan sistemática como pretende el autor y como parece a primera vista. A pesar de ser concebido como un estudio clínico y a pesar de haber organizado sus ideas en un plan arquitectural de lógica aparente, en realidad, El Perfil es digresivo (por ejemplo, cuando Ramos habla de la importancia de la religión en México o en las largas citas), repetitivo (por ejemplo, en cuanto a la imitación cultural que se explica tanto en el primer capítulo como al principio del cuarto capítulo), discontinuo (las diferentes partes de cada capítulo no se enlazan y constituyen a menudo conjuntos de por sí) e inconcluso (Ramos añadió en la segunda y tercera ediciones nuevos capítulos).

Pues bien, volviendo sobre nuestra pregunta de saber si el texto de Ramos se caracteriza por la estructura abierta típica del ensayo, concluimos que hay una voluntad explícita de desarrollar la reflexión acorde con un método sistemático, por un lado, y una organización subyacente de los materiales que se puede caracterizar como digresiva, repetitiva, discontinua e inconclusa, por otro.

\subsection{El estilo personal del ensayo}

La personalidad del ensayista no solo está presente en la selección del tema al que se dedica el ensayo, sino también en la elaboración del estilo. El ensayista proyecta su propia personalidad en la selección de las palabras, en el uso de determinados giros estilísticos, en la forma que da a sus pensamientos. Así es que la expresión estilística por parte del ensayista concede a la vez valor estético y autenticidad personal al ensayo (TdE 18). "En el ensayo, más que en ningún otro género literario, el estilo es el hombre, y será tanto más meritorio cuanto con más exactitud represente al hombre de carne y hueso que palpita en sus páginas." (TdE 18) El valor del ensayo no se tiene que buscar en la temática tratada, sino en la manera en la que se presenta y se expresa la materia tratada.

¿En qué medida se reconoce esta voluntad de estilo caracterizador del ensayo en El Perfil? Lo particular del estilo de El Perfil consiste en la omnipresencia de la ciencia, motivo predominante de las figuras estilísticas usadas en el texto. Ramos suele recurrir a comparaciones y metáforas relacionadas con el mundo de las ciencias exactas: zoología, botánica, ciencias naturales, biología, medicina, química, matemáticas. 
Otra fuente de inspiración frecuente es el mundo de la técnica, de máquinas, mecánica y aparatos. A modo de ejemplo, nos limitamos a algunas comparaciones. En primer lugar, Ramos justifica la inserción de algunas expresiones groseras del 'pelado' mediante una comparación en la que afirma que rehusar por pudor el estudio de las expresiones crudas del pelado, "sería como si un químico rehusara analizar las substancias que huelen mal" (El Perfil, 79). Más adelante, Ramos plantea que "el indio es como esas substancias llamadas catalíticas que provocan reacciones químicas con sólo estar presentes" (85). A continuación, explicando cómo se debe lograr una síntesis cultural, Ramos aduce que "entre el proceso de la imitación y de la asimilación existe la misma diferencia que hay entre lo mecánico y lo orgánico" (23). Hablando del individualismo del español, concluye que "cada español parece un átomo rebelde cuyo movimiento tiende a separarlo de su centro natural de gravitación" (28). Finalmente, Ramos refiere que los librepensadores introdujeron en México "un sistema de ideas en que pudiera verse, como en el vidrio despulido de un aparato fotográfico, la proyección invertida del sentimiento religioso" (112).

Comprobando, pues, que Ramos cubre sistemáticamente sus comparaciones con una lámina de ciencia, concluimos que se empeña en presentar las figuras estilísticas no como aproximaciones artísticas y subjetivas al tema sino como elementos que refuerzan el carácter científico de su texto. Para aclarar el proceso de reorientación de lo poético hacia lo científico al que nos referimos, citemos una comparación particularmente reveladora desde este punto de vista. Esta metáfora se basa en un elemento tradicionalmente poético, estético (a saber una flor), que, gracias a la inserción de un elemento de la química, -al menos en apariencia-, se hace más científica: "Era [el positivismo] un planta exótica pero que encontraba aquí en la atmósfera oxígeno que la alimentara, y que por eso vivió" (118).

Cuando miramos otro aspecto del estilo, el léxico, es de notar que Ramos suele insistir en los procesos lógicos que está aplicando, -tales como la ejemplificación (79), la ilustración (58), la deducción (9), la comparación (94), la definición (30) o la concatenación lógica (17)-, denominándolos explícitamente cuando los usa. También son numerosas las referencias al carácter lógico de su razonamiento (138-17) o a la falta de lógica del razonamiento de otros. Y, lo que más salta a la vista es que Ramos suele mencionar que estos procesos lógicos "demuestran" su 
tesis o que proporcionan la "prueba" o la "corroboración" de su tesis. Pongamos un ejemplo que se sitúa en la introducción que precede al análisis del sentimiento de inferioridad del mexicano. Ramos advierte que no hay razón para que el lector mexicano se ofenda al leer su tesis sobre la inferioridad del mexicano y concluye la parte introductoria convirtiendo la posible ofensa del lector mexicano en la prueba por excelencia de la validez de su tesis sobre el complejo de inferioridad:

Si no obstante estas aclaraciones el lector se siente lastimado [al leer sobre la inferioridad del mexicano], lo lamentamos sinceramente, pero confirmaremos entonces que en nuestros países de América existe, como dice Keyserling, un primado de susceptibilidad; y así su reacción de disgusto sería la más rotunda comprobación de nuestra tesis. (El Perfil, 74-75; el destacado es nuestro)

A continuación, Ramos analiza sucesivamente el complejo de inferioridad del 'pelado', del 'mexicano de la ciudad' y del 'burgués mexicano'. Mediante la siguiente argumentación, "demuestra" que es la nacionalidad mexicana y no la clase social lo que crea el sentimiento de menor valía:

Pudiera pensarse que la presencia de un sentimiento de menorvalía en el pelado no se debe al hecho de ser mexicano sino a su condición de proletario [...] La prueba decisiva de nuestra afirmación se encuentra en el hecho de que aquel sentimiento existe en los mexicanos cultivados e inteligentes que pertenecen a la burguesía. (El Perfil, 83-84; el destacado es nuestro)

Las referencias en el vocabulario a las dos ciencias centrales de su método -la psicología y la historia- son una constante a lo largo de la obra. El ensayista, quien se dirige a lectores no-especializados en el tema, adopta un tono afectivo y amistoso y presta especial atención a la forma en la que expresa su pensamiento. Para ello, no se sirve de un vocabulario técnico. Ramos, en cambio, habla de psicología genérica, de mecanismos psicológicos, de una teoría psicológica, de una constitución mental, de un sistema psicológico, de una evolución histórica, de un fenómeno histórico, de un esquema evolutivo y de la historicidad. Por otro lado, este léxico raramente se hace especializado, es decir no se hace difícil de comprender para el lector no-especializado en la materia de la psicología 
o la historia. A pesar de las apariencias, el léxico de El Perfil no es pues verdaderamente científico, es decir, destinado a expertos en psicología o historia. Otro rasgo relacionado con el lector activo del ensayo es su carácter no-especializado.

Concluimos que la respuesta a la pregunta de saber si el texto de Ramos se distingue por el valor estético caracterizador del ensayo no es unívoca. Por una parte, se destaca una gran creatividad artística en el estilo de El Perfil, particularmente en el uso personal de metáforas y en la selección cuidadosa del vocabulario. Por otra, es de notar que en la elaboración de este valor estético y subjetivo predomina un gusto por términos relacionados con la argumentación lógica o por situaciones e imágenes relacionadas con la investigación científica.

\section{Conclusiones: Samuel Ramos y su actitud de rechazo frente al ensayo}

Todos los fenómenos que acabamos de describir ilustran la misma operación que consiste en sobreponer a los rasgos del texto una apariencia de método sistemático y validez científica. Los rasgos subyacentes a la capa científica tienen en común el vínculo con características que diferencian el ensayo del tratado científico. En el ensayo, no reina la objetividad, sino que la propia persona del autor se plasma en el texto porque de la fiabilidad de esta persona depende el carácter persuasivo del discurso: la imagen subjetiva del ensayista se convierte pues en un verdadero argumento. En cuanto a la estructura, el ensayo no se define como un género sistemático ni acabado sino que se suele destacar su carácter libre, fragmentario, parcial y discontinuo, que se construye a través de una interacción constante con el lector. La argumentación del ensayo es verosímil, esto es, carece de valor probatorio y son precisamente el lenguaje imaginativo, rico en figuras estilísticas, los argumentos emocionales y el carácter del ensayista, que compensan, en el discurso ensayístico, la falta de pruebas explícitas. Sin embargo, parece que Samuel Ramos tiene poca confianza en la eficacia de la perspectiva subjetivista, del carácter dialogal y de la voluntad de estilo del ensayo. Prefiere, al contrario, caracterizar su perspectiva sobre la materia como racional y científica, presentar su metodología como sistemática y rigurosa, orientar las figuras de estilo hacia el mundo de las ciencias exactas y de la técnica. Concluimos que Ramos intenta hacer pasar los argumentos de su discurso ensayístico por los mismos de un tratado científico, y lo hace 
disimulando los rasgos de sus argumentos que distinguen el ámbito de la ensayística del terreno del tratado científico, por un lado, y construyendo una red de referencias a su supuesto razonamiento lógico, por otro.

Volviendo sobre la pregunta acerca del vínculo entre el género ensayístico y la reflexión acerca de la identidad mexicana, comprobamos que en el caso de El Perfil de Samuel Ramos, el ensayo dista de recalcarse como género idóneo para la definición de lo mexicano. Todo lo contrario: Ramos parece recurrir a varias estrategias para alejar el texto de la forma literaria del ensayo y aproximarlo, en la medida de lo posible, a la forma del tratado científico. Desde el punto de vista racionalista que el autor de El Perfil insiste en adoptar, el hecho de que Ramos reaccione contra las características intrínsecas de un género libre, abierto, subjetivo, híbrido, escurridizo y difícil de clasificar no debe de sorprendernos. Hay que recordar que varias mentes lógicas -Pascal por ejemplo- han reprochado al ensayo su falta de método. Pero según nuestra hipótesis, el rechazo por parte de Ramos de la forma literaria del ensayo se explica, más concretamente, en el contexto filosófico mexicano de los años treinta. Proponemos que su reacción frente al género ensayístico se debe entender en el marco histórico de la reflexión acerca de la mexicanidad y en la dinámica que se establece entre un enfoque más científico sobre el tema de la mexicanidad y un abordaje más romántico del mismo tema. ${ }^{7}$

Ramos asocia el ensayo con el utopismo de los pensadores Caso y Vasconcelos que se oponen al positivismo y al régimen de Porfirio Díaz. Antonio Caso rechaza la ciencia como posible instrumento para acercarse a la esencia mexicana: "[...] un pueblo que se educa nomás en la ciencia; es un pueblo sin entusiasmo, sin ideal. La ciencia es puro egoísmo, interés de conocimiento, propósito siempre reiterado de pensar. [...]" (Caso, 155). José Vasconcelos también se aleja del método científico al conceder en su pensamiento un lugar importante a la intuición: para él conocer las cosas no es razonarlas sino sentirlas. El pensador se orienta hacia la emoción como motor de la realización del proyecto mexicano: "corresponde a una raza emotiva como la nuestra sentar los principios de una interpretación del mundo de acuerdo con nuestras emociones"

7 En relación con esta dinámica entre racionalismo y romanticismo, conviene mencionar que el desarrollo del ensayo como realización híbrida y subjetiva se vincula estrechamente con el avance del espíritu romántico: el género se considera "el resultado del proceso de subjetivización artística y filosófica instituido desde las primeras generaciones prerrománticas" (Aullón de Haro, 22) y se inscribe, en este sentido, en la línea del rechazo por parte de los románticos Goethe, Dilthey de los métodos de matematización por lo que atañe a las ciencias del espíritu. 
(Vasconcelos citado por Castro Leal, 15). Ramos, al contrario, subraya las calidades racionales, tales como la sistematicidad y el método, como rasgos que diferencian su trabajo del de Caso y Vaconcelos. Refiriéndose a sus maestros antipositivistas, el propio Ramos reconoce en su artículo "Incipit vita nuova"(1925), por un lado, las deudas de su generación respecto de sus predecesores, pero por otro, subraya que su trabajo será al mismo tiempo menos romántico y más sistemático ("Incipit", 5). Refiriéndose a la polémica nacionalista que conoció su momento culminante en 1932, Ramos destaca que "la confusión que había creado esta polémica subrayaba aun más la necesidad urgente de un método que de modo científico podía revelar la autenticidad mexicana" (Historia, 51).

Dicho debate, analizado a fondo por Díaz Arciniega, es un marco fundamental para la concepción metódica de la obra de Ramos. La insistencia en el método de Ramos puede entenderse como una reacción contra el propio carácter caótico y no metódico de la controversia. Efectivamente, la polémica entre nacionalistas y europeístas en torno a la esencia mexicana es confusa, emocional y los argumentos utilizados muchas veces carecen de lógica. Así es que, incluso si algunos participantes en la polémica defienden una tesis parecida a la que expone Ramos en su Perfil, lo que falta por completo en aquellas contribuciones es la ambición de calidad filosófica, de validez metódica y el intento de una organización formal sistemática. Refiriéndose a la polémica nacionalista que conoció su momento culminante en 1932, Ramos destaca que "la confusión que había creado esta polémica subrayaba aun más la necesidad urgente de un método que de modo científico podía revelar la autenticidad mexicana" (Historia, 51). En breve, Ramos ("Incipit", 5), en una reacción contra el utopismo y el romanticismo de sus maestros pretende sustituir el estilo libre de Caso y Vasconcelos por una reflexión metódica. En el mismo sentido, en su libro Hipótesis (1928), Samuel Ramos se distancia de la irracionalidad, la emoción y la intuición presentes en el trabajo de sus predecesores, destacando que "fue un tanto equivocado abogar por la intuición en un país en el que hace falta la disciplina de la inteligencia" (Villegas, 112). Según Bartra (122-123), es efectivamente el alejamiento de las características de sus predecesores, -tales como el romanticismo, la exaltación irracional del sentimiento, la emoción y la intuición-, que se reconoce como la más destacada contribución de Samuel Ramos a la reflexión en torno a la identidad mexicana. 
El ensayo, "la ciencia sin la prueba explícita”, según la feliz fórmula de Ortega y Gasset -debido a la falta de valor probatorio de los argumentos, a la libertad de su desarrollo y al recurso a argumentos emocionales, subjetivos y expresivos- no goza, desde el punto de vista racionalista, del prestigio del tratado científico. Esta valoración inferior del ensayo tiene sus raíces en la posición intermedia que ocupa el ensayo entre la ciencia y la literatura, entre la razón y el arte (Arenas Cruz, 17 ; Aullón de Haro, 17). Recordemos, en este contexto de la posición fronteriza del ensayo, cómo Lukács (1911) ha propuesto la inclusión del ensayo entre los géneros artísticos mientras que Adorno (1958) ha abogado a favor de la revitalización del ensayo en un contexto académico.

Pero: ¿es la reflexión libre desarrollada en el género ensayístico de verdad un razonamiento inferior desde el punto de vista de la persuasión? ¿Es de verdad tan superior el tratado científico bajo esta perspectiva de la fuerza perlocutoria? El ensayo, aprovechando "las posibilidades intermedias entre los géneros científicos y los géneros artísticos, entre la tensión antiestándar del lenguaje artístico y la univocidad denotativa promovida por el lenguaje científico, entre la fenomenología y los hallazgos de la poeticidad, de un lado, y la cientificidad, por otro" (Aullón de Haro, 19), ofrece la ventaja de concebirse en función de la totalidad de la persona del receptor, a la vez un ser racional, pasional y contextual. El ensayo, desde el enfoque del acto perlocutorio y a pesar de lo que parece suponer Samuel Ramos, suministra más bien los medios adecuados para conseguir la persuasión de la mente y del corazón del público de los intelectuales del México de los años treinta, involucrados en el proceso de la construcción de una nueva identidad nacional. El discurso ensayístico es concebido como una estructura cordida para convocar equilibradamente las cargas emotivas e intelectuales del lector. La supuesta 'inferioridad' de la reflexión ensayística que Ramos se empeña en camuflar, en una reacción contra la emotividad de sus predecesores filosóficos, es en realidad -igual que en la tesis sobre la esencia del mexicano (su complejo de inferioridad) que el propio Ramos defiendeúnicamente un sentimiento de inferioridad, cuyas características no tienen por qué ser escondidas. Como explica el propio Ramos: “eso no significa que el mexicano sea inferior, sino que se sienta inferior, lo cual es cosa muy distinta" (El Perfil, 163). 


\section{Referencias bibliográficas}

Adorno, Theodor. "El ensayo como forma". Revista Pensamiento de los confines 1 (1998). Universidad de Buenos Aires. Diótimo: 247-259.

Arenas Cruz, María Elena. Hacia una Teoría General del Ensayo: Construcción del Texto Ensayístico. Castilla, La Mancha: Universidad de Castilla La Mancha, 1998.

Aullón de Haro, Pedro. "El género ensayo, los géneros ensayísticos y el sistema de géneros." El ensayo como género literario. Cervera, Vicente, Belén Hernánez y Ma Dolores Adsuar (Eds.). Murcia: Universidad de Murcia: 2005, 13-23.

Aullón de Haro, Pedro. Teoría del ensayo. Madrid: Verbum, 1992.

Bartra, Roger. La jaula de la melancolía: identidad y metamorfosis del mexicano. México: Grijalbo, 1987.

Bolaños Cadena, Laura. La identidad perdida y otros mitos. México: Vila, 2001.

Béjar Navarro, Raúl. El mito del mexicano. México: Universidad Nacional Autónoma, 1968.

Caloca, Eloy. “La condición mexicana posmoderna: un nuevo conflicto ¿ser mexicano, ser posmoderno o mexicano, o ser posmexicano?" En Razón y Palabra [en línea] 2008, 13 (62), (Mayo-Junio). México: Instituto Tecnológico y de Estudios Superiores de Monterrey. Recuperado en: http://www.redalyc.org/articulo. oa?id=199520738015.

Caso, Antonio. Discursos a la nación mexicana. Obras completas. Tomo IX. México: UNAM, 1976.

. El problema de México y la ideología nacional. 1a ed. 1924. México: Cultura. Antología filosófica. México: UNAM, 1985.

Díaz Arciniega, Víctor. Querella por la cultura revolucionaria (1925). México: Fondo de Cultura Económica, 1989.

Fuentes, Carlos. Tiempo mexicano. México: Joaquín Mortiz, 1975. 
Genette, Gérard. Introduction à l'architexte. París: Seuil, 1979.

Gómez Martínez, José Luis. Teoría del ensayo. México: UNAM, 1992. Recuperado en: http: / / www.ensayistas.org/cricita/ ensayo/gomez

Guerrero, Julio. La génesis del crimen en México. México: Porrúa, 1999.

Hurtado, Guillermo. Dos mitos de la mexicanidad. Recuperado en: http: / / dianoia.filosoficas.unam.mx / files.6313 / 6978/3507/ DIA94_Hurtado.pdf

Llinás Álvarez, Edgar. Revolución y educación mexicana. La búsqueda de la identidad nacional en el pensamiento educativo mexicano. México: UNAM, 1978.

Monsiváis, Carlos. "Notas sobre la cultura mexicana en el siglo XX". En: Historia General de México. México: El Colegio de México, 303-476, 1976.

Paz, Octavio. El laberinto de la soledad, Postdata y Vuelta a El laberinto de la soledad. México: FCE, 1989.

Perelman, Chaïm y Olbrechts-Tyteca, Lucie. "Logique et rhétorique". Rhétoriques. Bruxelles: Université de Bruxelles, 63100, 1989.

Ramírez, Santiago. El mexicano, psicología de sus motivaciones. México: Grijalbo, 1977.

Ramos, Samuel. "Incipit vita nuova". La Antorcha 13 (37), 1925: 5-8. . Hipótesis. México: Secretaría de la Institución Pública, 1928. . Historia de la Filosofía en México. México: Imprenta Universitaria, 1943. . Antonio Caso, filósofo romántico. México: UNAM, 1946. . El Perfil del hombre y la cultura en México. México: Pedro Robredo, 1951.

Vasconcelos, José. La raza cósmica. México: Espasa Calpe, 1948.

Uranga, Emilio. Análisis del ser del mexicano. México: Porrúa, 1950.

Vasconcelos, José. La raza cósmica. México: Espasa Calpe, 1948.

Villegas, Abelardo. La filosofía de lo mexicano. México: UNAM, 1979.

Zea, Leopoldo. Conciencia y posibilidades del mexicano y otros ensayos. México: Porrúa, 1953. 